\title{
BATALHA DE BERNA (1954): \\ A LUTA PELOS SENTIDOS \\ DE IDENTIDADE NO CAMPO DE FUTEBOL
}

\author{
THE BATTLE OF BERNA (1954): THE STRUGGLE FOR IDENTITY MEANINGS IN \\ THE FOOTBALL FIELD
}

\author{
BATALLA DE BERNA (1954): LA LUCHA POR LOS SENTIDOS DE IDENTIDAD \\ EN EL CAMPO DE FÚTBOL
}

\section{Felipe Rodrigues da Costa*, Otavio Tavares ${ }^{\star \star}$, Antonio Jorge Gonçalves Soares***, Amarilio Ferreira Neto**}

\section{Palavras-chave}

Meios de comunicação de massa.

Futebol.

Poder.

Keywords

Mass media

Soccer.

Power.

Palabras clave

Medios de comunicación de masas.

Fútbol.

Poder.
Resumo: 0 artigo objetiva analisar as diferentes estratégias da imprensa brasileira para narrar a disputa entre Brasil e Hungria na Copa do Mundo da Suíça (1954). A análise dos textos publicados no $O$ Globo e na Folha de São Paulo revela a presença de uma discussão sobre o caráter nacional, a crença na superioridade das características "naturais" do futebol brasileiro em comparação com o "espírito de organização" dos europeus e a vitória húngara como resultado de um conluio europeu. Conclui que a imprensa elabora uma inversão da hierarquia entre natureza e cultura, estereotipando identificações em um contexto de relações de poder desequilibradas.

Abstract: The article aims at identifying, describing and analyzing different strategies of Brazilian press to narrate the dispute between Brazil and Hungary in the 1954 World Cup in Switzerland. The analysis of articles published in newspapers $O$ Globo and Folha de São Paulo reveals the presence of a discussion about national character, the belief in the superiority of the "natural" characteristics of Brazilian football in comparison with Europeans' "spirit of organization" and the Hungarian victory as a result of a European collusion. The study concludes that the press reverses the hierarchy between nature and culture, stereotyping identifications in a context of unbalanced power relations

Resumen: Objetiva identificar, describir y analizar las diferentes estrategias de la prensa brasileña para narrar la disputa entre Brasil y Hungría en la Copa del Mundo en Suiza (1954). El análisis de los textos publicados en O Globo y en Folha de São Paulo revela la presencia de una discusión sobre el carácter nacional, la creencia en la superioridad de las características "naturales" del fútbol brasileño en comparación con el "espíritu de organización" de los europeos y la victoria húngara como resultado de un acuerdo europeo. Concluye que la prensa elabora una inversión de jerarquía entre naturaleza y cultura, estereotipando identificaciones en un contexto de relaciones de poder desequilibradas.
*Universidade de Brasília, Brasilia, DF E-mail: fcostavix@gmail.com

**Universidade Federal do Espírito Santo, Vitória, ES.

E-mail: tavaresotavio@yahoo.com.br

${ }^{* * *}$ Universidade Federal do Rio de Janeiro, Rio de Janeiro, RJ. E-mail: ajgsoares@gmail.com

Recebido em: 12-04-2014 Aprovado em: 17-09-2014 (c) (1) (8) Licence 


\section{INTRODUÇÃOO}

O presente texto estabelece um diálogo com o artigo de Von der Lippe e MacLean (2008), o qual analisa o uso de estereótipos raciais e nacionais na cobertura de jornais ingleses, noruegueses e suíços a respeito da violência ocorrida no jogo Brasil e Hungria na Copa do Mundo de 1954, na cidade de Berna. A estrutura discursiva jornalística que cobriu o evento revela como os estereótipos invocados para caracterizar brasileiros e húngaros estavam lastreados por relações de poder assimétricas entre centro e periferias e entre as respectivas culturas de cada país; além de exalar um senso de ameaça aos códigos culturais dos europeus (VON DER LIPPE; MACLEAN, 2008).

Von der Lippe e MacLean (2008, p. 76) destacam como os jornais europeus, sobretudo os periódicos ingleses, narram o jogo entre o Brasil e a Hungria como uma ruptura do comportamento do "homem ocidental", pois, "de acordo com a visão dominante da mídia daquele tempo, [...] o homem ocidental era um ser racional que tinha dominado sua agressividade inata e agora preferia resolver disputas por meio da negociação e da razão superior". Neste contexto, o comportamento dos húngaros foi visto como algo parcialmente civilizado na medida em que se opunha ao ideal do cavalheiro burguês branco do mundo ocidental. O homem húngaro foi rotulado como aquele parcialmente refinado que havia incorporado as virtudes do industrialismo, mas ainda não tinha em sua estrutura de personalidade o ethos do capitalismo que dociliza as relações em função dos interesses (VON DER LIPPE; MACLEAN, 2008; HIRSCHMAN, 2002). A cobertura jornalística em relação aos brasileiros se desenvolveu a partir de uma "linguagem da hierarquia racial, da superioridade europeia, da volatilidade e da indisciplina negra, da falta de civilização, da habilidade e força muscular sem sentido tático e controle emocional" (VON DER LIPPE; MACLEAN, 2008, p. 89, tradução nossa). Com efeito, os brasileiros foram definidos como sujeitos indisciplinados, de sangue quente, selvagens e negros. Em contas finais, "os valores étnico-raciais hegemônicos da imprensa esportiva reafirmaram valores sociais dominantes, e como tais, da autoridade moral e política do centro e do norte da Europa ocidental" (VON DER LIPPE; MACLEAN, 2008, p. 87, tradução nossa).

Como sabemos, a construção da identidade remete a uma vinculação, necessariamente contextualizada, consciente e baseada em oposições simbólicas (MAGUIRE; POULTON, 1999, WEISS, 2001, DENHAM; DESORMEAUX, 2008). No plano do esporte internacional, 0 dilema identitário é dramatizado no desafio de distinguir os significados locais dos universais (ZUCAL, 2007). Norton (1997) propõe o conceito de identidade cultural como a relação do indivíduo com os membros de seu próprio grupo, que dividem uma mesma história, uma língua em comum e uma maneira mais ou menos consensual de entender a sociedade e os comportamentos dos indivíduos. Nesse contexto, diversos estudos têm direcionado seus esforços no intuito de compreender como a mídia, especialmente a impressa, tem enquadrado as narrativas de identidade cultural atribuindo-Ihe sentidos precisos e estereotipados. No passado e no presente, os diferentes esportes na mídia, principalmente nas competição esportivas entre os estados-nação, assumem a gramática da identidade nacional para criar emoção, adesão e participação dos diferentes segmentos de consumo (BARTHOLO; SOARES, 2006, TAVARES et al., 2007, SALVADOR; SOARES, 2009). No caso específico do futebol, Helal, Soares e Lovisolo (2001) demonstraram como as narrativas midiáticas brasileiras podem ser consideradas como discursos românticos e essencialistas daquilo que se imagina como características bastante singulares. 
Como as seleções nacionais podem ser entendidas como metonímias dos estados-nação (HOBSBAWN, 1998) e a identidade é construída socialmente em contextos específicos, determinando a posição dos atores sociais e orientando suas escolhas em relação a um "outro" (CUCHE, 2002), torna-se significativo examinar como o mesmo embate entre Brasil e Hungria foi tratado pelos jornais brasileiros, explorando como narrativas de identidade nacional foram produzidas e definidas sobre o mesmo evento analisado a partir dos jornais europeus por Von der Lippe e MacLean (2008). A hipótese levantada é que a imprensa brasileira, ao fazer a cobertura do jogo, passa a narrá-lo a partir de uma gramática de identificações que organiza e atribui significados à equipe, ao jogo e a população, posicionando o 'brasileiro' em relação a seus 'outros', nesse caso, os húngaros e os europeus no contexto da época.

\section{MÉTODOS}

Selecionamos dois jornais para este estudo: Folha de $S$. Paulo e $O$ Globo, periódicos de grande circulação nacional que cobriram o evento na época. Os jornais foram analisados com publicações entre os dias 19 de junho e 3 de julho de 1954.

O jornal Folha de S. Paulo apresenta sua primeira edição tratando do jogo no dia 22 de junho de 1954, enquanto $O$ Globo o faz no dia 21 de junho. Foram analisados 39 textos de Folha de S. Paulo e 78 do jornal O Globo'.

Buscamos construir uma interpretação hermenêutica da enunciação de elementos narrativos da identidade nacional por meio do esporte nos textos jornalísticos sobre o jogo Brasil e Hungria de 1954. A análise evidenciou três momentos discursivos inter-relacionados: a derrota do Brasil na final da Copa de 1950 como uma referência contextual, o embate entre o talento brasileiro versus a organização europeia e o resultado do jogo como um conluio europeu. 0 eixo da análise reside na questão teórica central: a construção da identidade nacional como algo contextualizado e relacional. Nestes termos, de maneira adicional a esse corpus documental, tomamos como referência comparativa o artigo de Von der Lippe e MacLean (2008), procurando entender se e como os discursos da imprensa brasileira reconfiguram as hierarquias e relações de poder assimétrico em função da elaboração de uma identidade ou de um caráter da nacionalidade identificados pelos autores acima mencionados.

\section{TRAUMA DE 1950}

Uma parte significativa da discussão sobre a preparação das equipes para o jogo Brasil e Hungria da Copa de 1954 centra-se mais nas condições psicológicas da equipe brasileira para enfrentar o embate decisivo do que em elementos técnicos e táticos das duas equipes. Para entender esse tipo de comportamento da imprensa é preciso considerar os significados que a derrota do Brasil teve na Copa do Mundo anterior. Em 1950, o Brasil sediou a Copa do Mundo de futebol, o Estado vislumbrava nesse investimento auferir lucros simbólicos na direção da consolidação da brasilidade e da difusão da imagem para fora de um país que caminhava em direção ao desenvolvimento ${ }^{2}$. A gestão do evento, a construção do Maracanã e a impecável campanha da seleção brasileira antes do jogo decisivo eram motivos para 0 discurso ufanista sobre o potencial do Brasil frente ao mundo desenvolvido. A vitória naquela

1 Todos os textos analisados são assinados por enviados especiais dos jornais ou de agências de notícias.

20 discurso sobre a brasilidade vinha sendo bem agenciado desde o período varguista. 
Copa seria mais uma prova do potencial da nação frente ao mundo. $O$ discurso do prefeito do Rio de Janeiro, Mendes de Moraes, proferido imediatamente antes do jogo final da Copa entre Brasil e Uruguai, indicava as ambições que se projetavam naquele momento:

Brasileiros, vós que daqui a alguns minutos sereis campeões do mundo; vós que não tendes rivais em todo o planeta; vós a quem eu já saúdo como vencedores, cumpri minha palavra construindo este estádio. Cumpram agora o dever de vocês conquistando a Copa do Mundo (SANDER, 2004, p. 289).

A derrota para a Seleção Uruguaia naquele jogo foi vista como uma tragédia e marca da inferioridade psicológica do brasileiro como algo inevitável (NOGUEIRA et al., 1994).

A interpretação para uma derrota tão improvável girou em torno do debate sobre a insegurança atávica do caráter nacional. Essa percepção de um complexo de inferioridade que se materializa em situações de comparação com o estrangeiro foi traduzido por Nelson Rodrigues, importante dramaturgo e jornalista brasileiro, como o "complexo de cachorro vira-latas".

As derrotas nacionais por um bom tempo foram explicadas por uma leitura de tipo psicológica do caráter nacional. Nessa direção, o brasileiro seria o melhor do mundo no que diz respeito à técnica do futebol, porém o momento de decisão exigia mais do que ter o domínio de técnicas corporais; o que faltava ao brasileiro era, nos momentos cruciais, o controle e a vontade para obter sucesso. Nelson Rodrigues (1993) trata as derrotas para Uruguai, em 1950, e Hungria, em 1954, sob o prisma totalizante do caráter nacional:

E não era uma pane individual: era um afogamento coletivo. Naufragaram, ali, os jogadores, os torcedores, o chefe da delegação, a delegação, o técnico, o massagista. Nessas ocasiões, falta o principal. Estão a postos os jogadores, o técnico e o massagista. Mas quem ganha e perde as partidas é a alma. Foi a nossa alma que ruiu face à Hungria, foi a nossa alma que ruiu face ao Uruguai. [...] só um Freud explicaria a derrota do Brasil frente à Hungria, do Brasil frente ao Uruguai e, em suma, qualquer derrota do homem brasileiro no futebol ou fora dele. (RODRIGUES, 1993, p. 26, grifos nossos)

Essa questão ocupa o centro do debate que antecede o jogo de maneira quase obsessiva, pois não é um debate apenas restrito ao futebol, é um debate que fala da identidade nacional. Até a cobertura da preparação húngara para o jogo, em 1954, foi analisada a partir das intenções e das características psicológicas dos povos. A imprensa brasileira trazia informações de que os húngaros consideravam o jogo como uma vitória garantida, seja pela pouca preocupação com a ausência de Puskas, o principal jogador, (CHIORINO, 1954b), seja pelo fato do treinador húngaro ter marcado treinos preparatórios para a fase semifinal (BRÁS, 1954a). A imprensa brasileira lembrava que a arrogância desse favoritismo vislumbrado pelos húngaros era semelhante ao clima de vitória antecipada vivida pelos brasileiros antes da final da Copa de 1950.

Os jornalistas brasileiros, porém, esforçavam-se para demonstrar confiança na Seleção Brasileira, criticando o exagerado otimismo do adversário. Enveredando numa especulação de tipo psicológica, o jornalista Américo Mendes (1954) afirma que:

[...] os húngaros sempre foram sóbrios e comedidos nas suas impressões. Todos os adversários, inclusive a própria Coréia, Ihes mereceram respeito e a certeza absoluta da vitória não os levava a acreditar cegamente na derrota do onze contrário. De um momento para outro, houve uma mudança brusca. $\mathrm{O}$ técnico húngaro passou a encarar o Brasil como derrotado na véspera e tornou-se parlapatão [...]. 
Ou esse homem está desorientado ou, sentiu a necessidade de manter a confiança nos seus pupilos, por julgá-los sem ela, ou diante de uma tarefa acima de suas forças. (MENDES,1954, p. 7)

A alegada arrogância do treinador húngaro poderia ser lida como uma confirmação da superioridade brasileira que estaria perturbando a confiança dos jogadores. Por outro lado, 0 treinador brasileiro, Zezé Moreira, foi retratado com um otimismo sereno e confiante. A transferência da autoproclamada superioridade para os húngaros desta vez seria positiva, já que a ilusão da superioridade não corria o risco de acontecer com os brasileiros novamente.

Zezé Moreira consegue conservar a calma e esperar pelos acontecimentos. Esclarece: 'Felizmente, pela primeira vez em muitos anos, estamos disputando um certame sem ter o título assegurado antecipadamente'. E realmente o Brasil vai jogar com a Hungria sem a tradicional e ridícula faixa de campeão, e que vem sendo usada - talvez por excesso de otimismo - pelos magiares e seus fãs incondicionais [...] (SERRAN, 1954a, p. 10).

Tal como ocorria com o treinador brasileiro, havia entre alguns jornalistas brasileiros uma mal disfarçada esperança de que o favoritismo húngaro pudesse favorecer a Seleção Brasileira: "[...] nós já perdemos uma Copa do Mundo por nos julgarmos super-homens e agora, por sorte nossa, os super-homens são eles" (BRÁS, 1954a, p. 10).

A partir da experiência de 1950, que vai da euforia à frustração, o futebol brasileiro procurou se reconstruir para colocar-se em teste novamente na Copa de 1954. Parte da reconstrução se deu pela tentativa de uma preparação profissional e planejada da Seleção. Entretanto, para além das ações racionais e concretas, essa reconstrução da Seleção Brasileira teria sido também profundamente simbólica. Esse caráter simbólico das mudanças e da regeneração pretendidas evidenciou-se na decisão de mudar o uniforme da Seleção, substituindo as camisas brancas de 1950 pelas amarelas ou pela instauração em 1954 do ritual de beijar a Bandeira Nacional antes da entrada da equipe em campo (NOGUEIRA et al., 1994).

\section{A TÉCNICA VERSUS A ORGANIZAÇÃO}

O confronto Brasil x Hungria na fase de quartas de final foi proporcionado por um sistema de sorteio utilizado em Copas do Mundo na época. Segundo os jornais brasileiros, os próprios húngaros não queriam esse confronto de forma tão precoce, pois um dos quatro grandes favoritos seria eliminado "[...] antes da hora" (SILVA, 1954a). Para a imprensa brasileira aquele seria o principal jogo da Copa de 1954.

Entramos, afinal, na semana do grande jogo! No mundo inteiro se fala dele [...]. Estamos, sem dúvida, no ponto culminante do V Campeonato do Mundo.

Os brasileiros, pela excepcional campanha desenvolvida em 1950 - que nem 0 desastroso final empanou - e pelas vitórias de nossos clubes na Europa, mantêm bem alto o seu prestígio. Os húngaros por seu turno, há quatro anos vêm arregimentando credenciais. Encontram-se invictos, com uma série de mais de quarenta jogos, entre os quais contra a legendária seleção da Inglaterra (BRÁS, 1954a, p. 7).

Um dia antes do tão esperado jogo, as matérias dão evidências da crescente autoconfiança da imprensa brasileira. Chiorino (1954c) destacava em manchete: "Aumentam as esperanças: aprontou magnificamente a seleção nacional", relatando a excelente preparação 
e movimentação da equipe brasileira no último treino. A própria expressão "jogo do século", utilizada em outra manchete para se referir ao jogo, indica o grau de importância dado a ambas equipes por uma imprensa que não vê vencedor antecipado (MENDES, 1954).

Para além do componente técnico, que fazia desse jogo um evento imperdível, a imprensa nacional apresentava elementos que delineavam até certo ponto também um confronto entre natureza e cultura. Brás (1954a, p. 7) afirma que o Brasil estaria representando "[...] a malícia, o pendor natural de sua gente para o esporte das multidões [e] a Hungria retratando o espírito de organização dos europeus". Essa crença no talento 'natural' do jogador brasileiro - uma metonímia do povo brasileiro - ganha um caráter reconfirmatório quando textos da imprensa internacional são citados pelos jornais brasileiros de maneira acrítica, antes da própria partida.

Falando sobre os brasileiros, 'La Tribune', de Lausanne, escreveu que os brasileiros terão ainda muito o que fazer para rivalizar com os europeus, no domínio da homogeneidade conjuntiva. Em compensação o virtuosismo individual dos brasileiros foi, para nós, uma descoberta. Na falta da homogeneidade coletiva, os brasileiros deram mostras de uma técnica leve, sutil, espetacular, feita de improvisações, e facilitadas (sic) pela elegância de estilo. São insuperáveis no jogo de cabeça, graças a seu valor atlético natural e sua flexibilidade felina (DIÁRIO..., 1954, p. 10).

Apesar dos quatro anos de invencibilidade e do título olímpico da modalidade conquistado em 1952, a imprensa brasileira considerava inconcebível que os húngaros tivessem uma equipe melhor que seu selecionado nacional. Para a Folha de S. Paulo, não se poderia conceber que "[...] sem intercâmbio contínuo com os sul-americanos, possam os húngaros avançar tanto, na técnica do jogo, a ponto de se tornarem os mestres do mundo de uma hora para outra" (BRÁS, 1954d). Essa ênfase na superioridade técnica individual e na capacidade de improviso ignorava as críticas europeias à maneira de jogar à brasileira, caracterizada pela ausência do senso de coletividade (SOARES; LOVISOLO, 2003, DAMO, 2006), a qual nem a derrota para os húngaros foi capaz de abalar.

Na matéria intitulada "Eliminada a seleção brasileira em um jogo no qual deixou patente a sua superioridade" (ELIMINADA..., 1954, capa), pode-se ler que "[...] os húngaros foram inferiores em todos os pontos de vista. Admitimos o valor do futebol magiar, mas a técnica brasileira é insuperável". Nem mesmo a derrota para a Hungria alterou o convencimento de que, embora o jogo fosse coletivo, a técnica individual era a evidência da superioridade do futebol brasileiro. Essa tradição de ler o futebol brasileiro como detentor de uma técnica singular dissemina-se como gramática do futebol nacional para dentro e para fora (SOARES, 2014).

Isso nos permite pensar que a associação da identidade nacional ao polo da natureza foi certamente bem-aceita, uma vez que ela não era vista necessariamente como algo negativo, mas como o que criava as diferenças e distinções em relação ao "outro".

Segundo Von der Lippe e MacLean (2008), os jogadores brasileiros foram retratados pelos jornais ingleses, noruegueses e suíços como "tecnicamente brilhantes" e "indisciplinados", mas ao mesmo tempo "primitivos" e de "sangue-quente". A chave mobilizada pelos jornais europeus para explicar os comportamentos do time brasileiro são estereótipos raciais que tinham como pano de fundo a hierarquia entre culturas cujo centro era a Europa do norte. como seus homólogos do sul da Europa (VON DER LIPPE; MACLEAN, 2008, p. 84). 
Isso se torna também evidente nas narrativas que tratavam os húngaros como mais civilizados quando comparados com os sul-americanos. Entretanto, quando a comparação se radica na própria Europa, torna-se possível produzir um "outro" distinto, incompleto em termos civilizatórios e de seus valores sociais dominantes.

\begin{abstract}
Os húngaros estão situados perto do centro, mas não o bastante para estar sequer perto de serem 'um de nós', nem o tipo certo de Brancos. Como resultado, os estereótipos desse time incluíam características mais positivas do que as dos brasileiros 'cabeças negras', tais como 'disciplina fabulosa', uma 'máquina de defender' com um 'jogo mais refinado'. Esse refinamento do Norte é parcial. Os húngaros são 'manhosos como uma raposa'. Isso se deve ao fato de esses homens terem participado de uma luta fora das regras do futebol. Desse modo, eles não conseguiram controlar seu temperamento. Eles têm o oposto das características prescritas do cavalheiro burguês branco do mundo ocidental. Eles apresentam as virtudes do industrialismo, mas não as do capitalismo (VON DER LIPPE; MACLEAN, 2008, p. 84, tradução nossa).
\end{abstract}

\title{
5 A BATALHA DE BERNA
}

Segundo Von der Lippe e MacLean (2008), a imprensa europeia analisada retratou o jogo como uma reunião de equipes de duas culturas com déficits civilizatórios diferenciados em relação a uma ordem moral dada como superior. Tais narrativas, por meio de estereótipos nacionais e raciais, reforçam relações de poder assimétricas em um contexto de ameaças aos verdadeiros valores civilizadores materializados no esporte moderno.

Para os jornais brasileiros, como vimos, a partida seria um confronto da técnica individual do jogador brasileiro contra a capacidade de organização tática europeia que terminou com a vitória húngara por $4 \times 2$. Como a imprensa brasileira narra e explica mais essa derrota nacional representada pelo futebol?

O jornalista de O Globo, Ricardo Serran, dois dias antes do jogo (1954b), afirmou que "[...] na direção da luta funcionará o juiz inglês Arthur Ellis, o que constitui uma boa recomendação para a normalidade da peleja". No entanto, após o jogo, ele garante que nunca teve dúvidas sobre o perigo de árbitros europeus apitando jogos de equipes também da Europa, atestando ainda que a FIFA teria suas equipes "preferidas", e a seleção húngara estaria cercada "[...] de todos os cuidados e proteções até a finalíssima" (SERRAN, 1954c, p. 10).

Na capa da mesma edição, abaixo de uma foto do goleiro brasileiro Castilho chorando, O Globo traz o segundo motivo que teria aniquilado as chances do Brasil: a violência. Ao contrário das narrativas analisadas por Von der Lippe e Maclean (2008), segundo os jornalistas de O Globo e da Folha, foram os húngaros os responsáveis por entradas desleais e agressões aos jogadores brasileiros. Nesse ponto, as narrativas do jogo ganham conteúdo diferenciado. Enquanto os jornais europeus atribuem aos jogadores brasileiros o protagonismo pela violência em campo, explicado por suas características raciais e padrão cultural limitado, para a imprensa brasileira, são os húngaros os grandes agressores. Além disso, foi "[...] um verdadeiro combate para os jogadores brasileiros, que tiveram pela frente um conjunto decidido a conquistar através de meios lícitos e ilícitos a vitória, e um juiz parcial, favorecendo de forma indigna 0 quadro húngaro" (ELIMINADA..., 1954, capa). 
O articulista de O Globo, Serran (1954c, p. 10) disse que o "Mr. Ellis truncou a peleja de ontem, em Berna, facilitando a vitória dos húngaros - dois goals em off-side e um penalty inexistente permitiram aos magiares o placard (sic.) de quatro a dois". O pênalti a que se refere o jornal foi marcado pelo árbitro quando o jogo estava $2 \times 1$ para a Hungria:

Graças a essa penalidade máxima, os húngaros puderam ampliar a diferença no placard para $3 \times 1,0$ que quebrou bastante a reação que vinham entusiasticamente empreendendo os nossos jogadores. Mesmo assim o Brasil ainda chegou aos 3x2, para acabar capitulando por $4 \times 2$ em virtude de outro erro do juiz, validando um gol de offside do meia Kocsis (O PENALTY..., 1954).

A violência em campo se alongou até os vestiários após a partida. Todavia, as narrativas da imprensa brasileira são pouco detalhadas a respeito desses eventos. O jornal Folha de $S$. Paulo informa que a confusão após o jogo foi criada pelo atacante húngaro Puskas, que teria atirado uma garrafa na testa do zagueiro brasileiro Pinheiro. Mesmo com a intervenção da polícia, as delegações das seleções entraram em confronto físico nos vestiários (SERRAN, 1954e).

Existem indícios para pensarmos nas inconsistências presentes nas matérias publicadas pela imprensa brasileira, pois estas eram destinadas a apresentar, consciente ou inconscientemente, ao leitor nacional uma narrativa que explicasse de forma adequada como a superioridade do futebol nacional caiu por terra em Berna. A expressão "truncou a peleja" significa que o árbitro teria marcado um número excessivo de faltas, sendo rigoroso demais e impedindo o bom desenvolvimento da partida. Essa reclamação é contraditória à reclamação de violência por parte dos húngaros e, especialmente, à respectiva complacência de Mr. Ellis com esse comportamento.

O Globo e Folha registraram a opinião dos húngaros acusando os jogadores brasileiros por terem iniciado os ataques dentro de campo. Todavia, os periódicos não tomam a violência como causa da derrota nacional. A derrota tinha nome e nacionalidade, Mr. Ellis, o árbitro inglês, aquele que teria prejudicado a seleção por seus erros, pela incapacidade técnica e pelo comprometimento moral.

De maneira oposta, como demonstraram Von der Lippe e MacLean (2008), quando comparações entre sul-americanos e europeus são feitas pelos jornais suíços, noruegueses e, sobretudo, ingleses, há uma distinção clara sobre o caráter dos povos. Os periódicos ingleses foram mais incisivos, na época, sobre o caráter e a moral dos "outros povos". Por serem os construtores e difusores do esporte moderno se sentiam autorizados a estabelecer a "régua da civilidade" também no futebol:

Os ingleses reclamam a propriedade do futebol e afirmam o direito de definir e prescrever os códigos morais e a prática ética associada a ele. Um status mais elevado e um poder moral maior são reclamados pelo futebol inglês especificamente e o futebol britânico em geral à medida que proclamam o futebol com uma marca de 'inglesidade' ${ }^{3}$ e dados os termos da repetida recusa da Associação de Futebol Inglesa e seus aliados na Escócia, Gales e Irlanda em participar das primeiras Copas do Mundo e também sua tensa e espasmódica participação na FIFA. Essas afirmativas de superioridade moral e a ampla adesão aos códigos culturais do imperialismo popular significaram que os jornais ingleses provavelmente encontraram uma audiência simpática para suas reclamações que, a despeito da qualidade das equipes, não poderiam resistir a jogar com violência (VON DER LIPPE; MACLEAN, 2008, p. 79, tradução nossa) 
Esse ideal de "inglesidade" está refletido no discurso sobre o trabalho do árbitro, Mr. Arthur Elliot, auxiliado pelo também inglês Mr. W. Ling, no controle da partida, tal como identificado por Von der Lippe e MacLean (2008, p. 80, tradução nossa). De acordo com o jornal The Manchester Guardian, o árbitro trabalhou para a manutenção da lei e da ordem. The Daily Mail na primeira página estabelece: "O derramamento de sangue só foi evitado no campo de jogo devido à bravura de um inglês, Sr. Arthur Ellis, o árbitro de Halifax, que estava encarregado do jogo, com o Sr W. Ling, de Cambridge, um de seus auxiliares".

Serran (1954c, p. 10), entretanto, um dia após a derrota, sintetiza aquele que teria subtraído aos brasileiros a chance de disputar o título de campeão mundial de futebol: "Derrotados os brasileiros pelas falhas da arbitragem". De fato, o papel do árbitro, quando narrado a partir da imprensa brasileira, assume características bastante diversas. Para ela, não foram os húngaros que derrotaram os brasileiros, mas sim Arthur Ellis. Segundo matéria publicada na Folha em 29 de junho, a "calamitosa" atuação do árbitro teria influenciado o resultado: "O resultado final não espelha de forma alguma o andamento da peleja, uma vez que foi conquistado com o evidente auxílio do árbitro, o célebre Mister Ellis, cuja fama deve ter sem dúvida ruído com a atuação facciosa desta tarde" (ELIMINADA..., 1954, capa).

Os jornais brasileiros acusam, sem nenhum distanciamento ou pudor, a arbitragem de conivente com a violência da equipe húngara. Para os jornalistas brasileiros, se 0 árbitro tivesse agido com imparcialidade, o resultado teria sido outro:

O juiz Ellis finalmente coroou sua atuação desastrada com a expulsão de Nilton Santos e com a de Humberto, ambos agredidos e não agressores, e não assinalando o impedimento de Kocsis, na ação do quarto tento magiar, e a penalidade máxima cometida por Zakarias em Julinho, aos 39 minutos da segunda fase.

Nestas condições é das mais lamentáveis a tarefa de comentar uma peleja vencida por um quadro inferiorizado no gramado sob todos os pontos de vista. A torcida suiça não regateou aplausos aos brasileiros, foi unânime em reconhecer que foram estes os verdadeiros vencedores do encontro (ELIMINADA..., 1954, capa).

Em outra edição do jornal, dias após a partida, Serran (1954c, 1954d) seguiu discutindo os erros cometidos pelo árbitro inglês, afirmando que estaria havendo uma repulsa unânime à arbitragem, e que os dirigentes brasileiros teriam enviado um protesto à Federação Internacional de Futebol (FIFA) contra Mr. Ellis.

Para a imprensa brasileira, a atuação do árbitro é "indigna", "facciosa" e indecente. 0 resultado da partida é visto como déficit moral tanto dos jogadores húngaros, quanto do árbitro. A linguagem da conspiração indica que a FIFA e o árbitro faziam parte de um conluio europeu para limitar as chances de sucesso dos brasileiros e dos sul-americanos em geral. Parece claro que o discurso dos jornais brasileiros sobre a derrota representou também a representação e a identificação da relação de poder assimétrica entre o centro (Europa) e a periferia (América do Sul), entre o norte e o sul na configuração do mundo.

Von der Lippe e MacLean (2008) indicam que as narrativas dos jornais europeus sobre o referido jogo e suas consequências foram construídas a partir de um tipo de seleção e enquadramento etnocêntrico, ainda presente naquela época, que colocava a Europa como 0 centro e referência do mundo civilizado em todas as esferas, mesmo esquecendo-se da recente barbárie provocada pelas duas grandes guerras. A imprensa brasileira operou um tipo de leitura da derrota para os húngaros a partir das narrativas da superioridade técnica do futebol 
brasileiro, da desonestidade do árbitro e da conspiração da FIFA e dos europeus em relação aos brasileiros e aos sul-americanos em geral. Enfim, os brasileiros teriam sido vítimas dos detentores do poder na configuração do mundo e do futebol internacional.

Observemos ainda que a produção do jornalismo, de ontem e de hoje, utiliza os próprios jornais, nacionais e internacionais, como fonte para cobrir os diferentes de eventos e fatos que merecem ser notícia. Os jornais brasileiros em 1954, sem fugir à prática do campo, utilizaram na produção de suas matérias sobre o jogo Brasil x Hungria diferentes jornais europeus como fonte. A imprensa brasileira, no uso desse recurso e tipo de fonte, apresentou as matérias dos jornais europeus que se coadunavam com as racionalizações aqui produzidas sobre aquela derrota e sobre o louvor, mesmo diante do infortúnio, do superior futebol nacional. Destaque-se que os estereótipos étnico-culturais sobre dos jogadores brasileiros apresentados pelos jornais europeus naquele jogo (VON DER LIPPE; MACLEAN, 2008) não foram fonte dos jornais brasileiros que observamos. Com efeito, em uma das poucas vezes em que se apresenta uma opinião europeia sobre o jogo, ela foi retrabalhada para reiterar o argumento da conspiração contra o time brasileiro. $O$ jornal $O$ Globo destacou a opinião do presidente da Liga Escocesa de Futebol e do Clube Glasgow Celtic, o Sr. Bob Kelly:

Os húngaros possuem uma boa equipe de football, porém acham que ninguém mais possa ter um bom team [...]. Na minha opinião [...] a Taça do Mundo é um completo desastre. Sua organização é caótica e a conduta dos jogadores já não tem remédio (A COPA..., 1954).

\section{CONCLUSÃO}

Podemos afirmar que, de forma diferente do que identificaram Von der Lippe e MacLean (2008), não é a partir da preocupação com um decaimento do esporte como um índice de civilização etnocentricamente determinado que se situam as narrativas da imprensa brasileira sobre a Batalha de Berna. As narrativas da imprensa brasileira são construídas a partir de uma perspectiva local, em uma dinâmica de produção e afirmação de uma identidade nacional na qual o futebol é um vetor totalizante, metonímia da nação.

A preocupação de fundo que antecede o jogo foi sobre a fragilidade da vontade do "homem brasileiro" e a sua capacidade da transformação da pretensa superioridade do futebol brasileiro em resultados. Essa seria, em primeiro lugar, a razão das derrotas até então ocorridas e a condição a ser superada. As narrativas brasileiras sobre a Batalha de Berna (Hungria 4 x 2 Brasil) delineiam relações de poder entre centro e periferia na qual teríamos sido destituídos de apresentar "nossas potencialidades" frente aos interesses escusos daqueles que representam o "centro": 0 árbitro europeu e a FIFA.

Em O Globo e na Folha de S. Paulo da época foram as características "naturais" e "singulares" do jogador e do futebol brasileiro que poderiam fazer a diferença e mesmo a vantagem em relação ao "espírito de organização dos europeus". Isso confirma a noção de que, pelo menos naquele contexto, as qualidades individuais, aquelas que traduziram o estilo de jogo brasileiro, eram mais valorizadas do que a organização coletiva e o planejamento tático.

O jogo no contexto de uma competição entre estados nacionais, para além da dinâmica intrínseca que determinou seu resultado, se tornou um estopim para os jornais de diferentes países acionarem 0 arsenal discursivo das identidades, estereotipias e estranhamentos dos 
vizinhos e dos distantes. A cara ideia da civilização ocidental e suas normas de civilidade, como medida de tudo ainda naquele contexto, era o que classificava e hierarquizava os indivíduos, as condutas e os povos. É a partir da noção de europeu e de civilização que o jogo ganha significado e racionalizações, tanto nos periódicos brasileiros quanto nos europeus. É verdade que a noção de civilização foi apropriada de diferentes maneiras naquele contexto, no caso brasileiro pensava-se a partir de Freyre, pois aqui instalávamos uma civilização original e singular (SOARES; LOVISOLO, 2003, SOARES, 2014). É no terreno das disputas identitárias que os jogos foram narrados e seus resultados foram interpretados desde 1950, no caso brasileiro. A configuração de uma competição que aciona naturalmente o mercado dos estados-nação acaba por obscurecer a análise dos fatores intrínsecos dos jogos e dos esportes quando esses são englobados pelas narrativas nacionais. Os resultados não são analisados a partir da organização tática nem pelo reconhecimento da técnica do "outro", uma vez que esses aspectos foram obliterados pelo clima nacionalista da estrutura desse tipo de competição pela mídia.

Em síntese, a interpretação que surge das análises inauguradas por Von der Lippe e MacLean (2008) e a que aqui empreendemos revelam como aquele mundo do pós-guerra tinha nas gramáticas totalizantes do nacional, do singular, do civilizado e do bárbaro as chaves de leitura das culturas e seus desdobramentos e enfrentamentos em qualquer espaço social que os estados-nação participassem competindo. Os jornais, ao narrarem a Batalha de Berna, acabam, cada um do seu lugar, explicitando as assimetrias entre centro e periferia e, no caso dos jornais europeus, as próprias assimetrias daquele continente ao observarem os húngaros. Esses seriam civilizados de segundo escalão.

No caso brasileiro, o futebol na Copa de 1950, na Batalha de Berna em 1954 e, talvez, ainda hoje, mobilize gramáticas que falem de projetos de nação e que tensionam a complexa e estereotipada ambivalência entre valores associados à sociedade tradicional e patriarcal, bem como dos valores associados às sociedades modernas e individualistas.

\section{REFERÊNCIAS}

BARTHOLO, Tiago Lisboa; SOARES, Antonio Jorge Gonçalves. Identidade, negócio e esporte no mundo globalizado: 0 conflito entre Guga e os patrocinadores na Olimpíada de Sydney. Revista

Brasileira de Ciências do Esporte, Campinas, v. 28, n. 1, p. 55-72, jul. 2008.

BRÁS, O. O blefe dos húngaros. Folha da Manhã, São Paulo, p. 7, 25 jun. 1954c.

BRÁS, O. A história se repete. Folha da Manhã, São Paulo, p. 7, 23 jun. $1954 b$.

BRÁS, O. Os super-homens. Folha da Manhã, São Paulo, p. 7, 22 jun. 1954a.

BRÁS, O. Vencer ou cair de pé. Folha da Manhã, São Paulo, p. 12, 27 jun. 1954d.

CHIORINO, Aroldo. Aumentam as esperanças: aprontou magnificamente a seleção nacional. Folha da Manhã, São Paulo, p. 7, 26 jun. 1954c.

CHIORINO, Aroldo. Com Puskas ou sem Puskas passaremos pelo Brasil. Folha da Manhã, São

Paulo, p. 7, 25 jun. 1954b.

CHIORINO, Aroldo. Como o Brasil de 1950... Folha da Manhã, São Paulo, p. 7, 25 jun. 1954a.

CHIORINO, Aroldo. O Brasil encaminha enérgico protesto à FIFA. Folha da Manhã, São Paulo, s/p, 29 jun. 1954d.

A COPA do Mundo é um desastre. 0 Globo, Rio de Janeiro, 30 jun. 1954. 
CUCHE, D. A noção de cultura nas ciências sociais. Bauru: Edusc, 2002.

DAMO, Arlei Sander. A magia da seleção. Revista Brasileira de Ciências do Esporte, Campinas, v.28, n. 1, p. 73-90, set. 2006.

DENHAM, Bryan; DESORMEAUX, Melissa. Headlining the head-butt: Zinedine Zidane/Marco Materezzi portrayals in prominent English, Irish and Scottish newspapers. Media, Culture \& Society, Londres, v. 30, n. 375, p. 375-392, May 2008.

DIÁRIO do campeonato do mundo. O Globo, Rio de Janeiro, p. 10, 21 jun. 1954.

ELIMINADA a seleção brasileira em um jogo no qual deixou patente a sua superioridade. Folha da Manhã, São Paulo, capa, 29 jun. 1954.

HALL, Stuart. Da diáspora: identidades e mediações culturais. Belo Horizonte: Editora UFMG, 2003.

HELAL, Ronaldo; SOARES, Antonio Jorge; LOVISOLO, Hugo. A invenção do país do futebol: mídia, raça e idolotria. Rio de Janeiro: Mauad. 2001.

HIRSCHMAN, Alberto. As paixões e os interesses: argumentos políticos a favor do capitalismo antes do seu triunfo. Rio de Janeiro: Record, 2002.

HOBSBAWN, Eric. Nações e nacionalismos. São Paulo: Paz e Terra, 1998.

MAGUIRE, Joseph; POULTON, Emma K. European identity politics in Euro 96: Invented traditions and national habitus codes. International Review for the Sociology of Sport, Londres, v. 34, n. 1, p. 17-29, Mar. 1999.

MENDES, A. O jogo do século não tem vencedor antecipado, Folha da Manhã, São Paulo, p. 7, 26 jun. 1954.

NOGUEIRA, Armando et al. A Copa que ninguém viu e a que não queremos lembrar. São Paulo: Companhia das Letras, 1994.

NORTON, Bonny. Language, identity, and the ownership of English. TESOL Quaterly, Washington, v. 31, n. 3, p. 409-429, 1997.

O PENALTY que aniquilou o Brasil. 0 Globo, Rio de Janeiro, 28 jun. 1954.

RODRIGUES, Nelson. Freud no futebol. In: CASTRO, Ruy (Org). À sombra das chuteiras imortais: crônicas de futebol. São Paulo: Companhia das Letras, 1993. p. 25-26.

SALVADOR, Marco Antonio Santoro; SOARES, Antonio Jorge Gonçalves. A memória da Copa de 70: esquecimentos e lembranças do futebol na construção da identidade nacional. Campinas: Autores Associados, 2009.

SANDER, Roberto. Anos 40: viagem à década sem copa. Rio de Janeiro: Bom Texto, 2004.

SERRAN, R. Agredidos os nacionais durante e após o jogo. 0 Globo, Rio de Janeiro, 28 jun. 1954e.

SERRAN, R. Derrotados os brasileiros pelas falhas da arbitragem. 0 Globo, Rio de Janeiro, p. 10, 28 jun. $1954 \mathrm{C}$.

SERRAN, R. Não há fantasmas no football. 0 Globo, Rio de Janeiro, p. 10, 24 jun. 1954a.

SERRAN, R. Repulsa unanime à arbitragem. 0 Globo, Rio de Janeiro, p. 10, 28 jun. 1954d.

SERRAN, R. Tudo pronto para a maior batalha da V Copa. 0 Globo, Rio de Janeiro, s/p, 26 jun. 1954b.

SILVA, G. R. Justificam-se os húngaros pelos incidentes. 0 Globo, Rio de Janeiro, p. 10, 28 jun. 1954b.

SILVA, G. R. Os húngaros preferiam o encontro mais tarde. 0 Globo, Rio de Janeiro, p. 10, 21 jun. 1954a.

SOARES, Antonio Jorge Gonçalves. Futebol: um estilo de jogo brasileiro?. In: MELO, V. A.; PERES, F. F.; DRUMOND, M. (Org.). Esporte, Cultura, Nação, Estado: Brasil e Portugal. Rio de Janeiro: 7 Letras, 2014. v. 1. p. 218-232.

SOARES, Antonio Jorge Gonçalves; LOVISOLO, Hugo. Futebol: a construção histórica do estilo nacional. Revista Brasileira de Ciências do Esporte, Florianópolis, v. 25, n. 1, p. 129-143, 2003. 
TAVARES, Otávio et al. Frozen bananas: esporte, mídia e identidade brasileira nos jogos olímpicos de inverno. Revista Brasileira de Ciências do Esporte, Florianópolis, v. 29, n. 1, p. 193-208, 2007.

VON DER LIPPE, Gerd.; MACLEAN, Malcolm. Brawling in Berne: mediated transnational moral panics in the 1954 Football World Cup. International Review for the Sociology of Sport, Londres, v. 43, n. 1, p. 71-90, Mar. 2008.

WEISS, Otmar. Identity reinforcement in Sport: revisiting the symbolic interactionist legacy. International Review for the Sociology of Sport, Londres, v. 36, n. 4, p. 393-405, 2001.

ZUCAL, José Garriga. Entre identidades nacionales y locales: los simpatizantes de um club de fútbol argentino ante los avatares de su selección nacional. Papeles del CEIC, Biscaia, v. 2, n. 30, set. 2007. 